\title{
Research into harmful effect of underground mining operations on the state of buildings and structures located in the displacement area
}

\author{
Oleksandr Dolgikh ${ }^{1 *}$, Liubov Dolgikh ${ }^{1}$, and Ivan Kuchnerov ${ }^{2}$ \\ ${ }^{1}$ Kryvyi Rih National University, Department of Mine Surveyin, 11 Matusevycha St., 50027 Kryvyi \\ Rih, Ukraine \\ ${ }^{2}$ Kryvyi Rih National University, Department of Underground Mining of Mineral Deposit, \\ 11 Matusevycha St., 50027 Kryvyi Rih, Ukraine
}

\begin{abstract}
An urgent task of both the mine surveyor service and the entire mining sector is to develop and implement in production the remote digital methods for monitoring the deformations of buildings and structures, which are located in areas influenced by underground mining operations. When developing a new methodology for determining the buildings and structures deformations, special attention is paid to improving the photogrammetric method. The study is aimed at determining the optimal conditions for digital imaging of buildings and structures in order to obtain the deformation values with the required accuracy. Based on the results of experimental work on the simultaneous different-scale images processing, the accuracy of determining the planimetric coordinates and heights of the studied points is much higher compared to the previously used methodology, in which digital models of an object are plotted from images obtained by a single camera lens, that is, with the same metric characteristics. The use of high degree of detail and fragmentation of large-scale images, as well as a significantly smaller number of small-scale images, covering the surveyed object, improve the accuracy of determining the position of points, which in turn affects the reduction of the error in combining the models.
\end{abstract}

\section{Introduction}

The iron ore deposit in the Kryvyi Rih Iron-ore Basin is developed by surface and underground mining methods. When mining a deposit by an underground method, the mining systems with the caving of ore and overlying rocks are used in the mines, which leads to the earth's surface disturbance. In the works $[1-5]$, the authors propose technologies for mining ore deposits, which can increase labour efficiency, iron content in the mined ore mass, reduce the production costs, but they lead to the creation of a displacement zone on the earth's surface. The changeover from systems of mining with massive caving to systems with an open stope space will reduce the displacement zone of the earth's surface, but will not stop its development as a result of the formed disturbances

\footnotetext{
*Corresponding author: dlavgeod@gmail.com
} 
in the rock massif. Therefore, in the works [6-10], the issue is studied of monitoring the displacement of mine rocks and day surface, as a result of the underground mining influence on them, and modern digital technologies are proposed to use for improving the efficiency of predicting the further state of these objects.

The "Pivdenna Mahnetytova" deposit in the mine allotment of the "named after Ordzhonikidze" mine is developed by a surface-chamber system with the caving of ore and host rocks, resulting in the formation of craters and fractures on the surface. It is known that negative human intervention in nature, in most cases, damages it, upsetting the balance. Recently, all of humanity has been worried about the consequences of interference with the laws and phenomena of nature. Scientists in our and other countries are studying the consequences of such aggressive intervention and developing measures to preserve the environment. This is the reason for the emergence of new research directions and objectives. Foreign scientists in the works [11-14] present an analysis of the harmful influence on the environment and propose the geophysical methods of research. Most of the scientists' research is devoted to studying the possibility of minimizing the negative impact of human activity on the environment and reducing negative economic consequences by proposing methods of nonlinear prediction, numerical analysis of the surface state [1518]. One of the most important tasks is to ensure the safety of people life and health. It is the rapid change in the environment by humans that leads to global and regional problems on the planet. Global warming is a dramatic example.

Different industries have different effects on the surrounding world, and most of them are harmful. This is the case of the mining industry, which also has a negative impact on the environment. That is, mining is also included in the list of harmful industries, but in most cases the consequences are observed, as a rule, not on a global, but on a regional basis (city, district, etc.). Human settlements with once full-flowing rivers, after water withdrawal from mine workings and transferring channel ways, have rivers that become shallow and disappear.

In addition, cultural and historical centers on the scale of a district or city are becoming depressive. This happened also with the present Horkoho village in Kryvyi Rih. Fractures and deformations appear in the buildings located in the zone of underground mining influence. The development of an effective method for preventing accidents, earth's surface displacements and damage to buildings is an urgent problem.

When the arch was collapsed and a crater was formed in 2010, the buildings entered the zone of displacements and cavings, which, according to preliminary calculations of the hazardous zone of displecement, should not have been in the hazardous zone. This made it necessary to clarify its boundaries, and consequently, according to the results of surveying observations and data from the mining and geological services, the zone of fractures and dangerous deformations has been corrected.

The results of instrumental measurements and visual observations performed by the authors of the paper made it possible to correct (update) the displacement angle value, which was previously calculated in accordance with the "Rules for the structures and natural objects protection from the harmful influence of underground mining in the "Kryvyi Rih Iron-ore Basin", developed by State Research Institute of Mining Geomechanics in 1975. SE "Kryvbasproekt", using the results of surveying observations and conclusions on them, in 2019 made a calculation of the zone of dangerous displacements above the minedout space resulted from mining the $527-607 \mathrm{~m}$ horizon of the field at the "named after Ordzhonikidze" mine. The method with the Digitals program, used by the authors, is more effective, since it requires much less time on computational and graphic work and enables presenting the results in a convenient form.

Since underground mining creates cavities that cause displacements and subsidence on the day surface, solving this problem has been an urgent task for a long time. In the works 
[19-21], the characteristics of ecological and economic losses from the influence of underground mining of minerals are presented, as well as the issues of reconstructing the structures in the areas of mining operations are considered. For today, most scientific works are aimed not only at increasing the efficiency of mining raw materials from the subsoil, but also to implement the methods of mineral deposits mining that minimize the harmful effects of underground mining on the environment, on the day surface state, where not only enterprises are located, but also objects of settlements $[22,23]$, as in the case with the objects of the name named after Horkoho village in Kryvyi Rih.

\section{Methods}

When studying the influence of underground mining of minerals on the state of the earth's surface, buildings and structures, considerable attention of scientists is focused on the application of radars and photogrammetric monitoring using light modern equipment [24-28]. In the works [29-30], it is proved that the accuracy of determining the deformation values using interferometric radars is: subsidence up to $1 \mathrm{~m}$; planned displacement up to $0.24 \mathrm{~m}$. Surveying and geodetic observations of such hasardous areas are performed in various ways: using linear measurements and leveling; using GPS; using electronic devices; using photogrammetric methods based on digital methods of imaging from unmanned aerial vehicles, etc.

It is known that the classical method with the use of linear measurements and leveling between the benchmarks of the observation station profile lines cannot always be applied because of the performer location in the hazardous zones of displacements and cavings. Today, the classic method of observation stations is used with the help of modern devices: electronic total stations - for measuring the distances between benchmarks and determining the elevations between them from trigonometric leveling according to the measured distances and tilting angles, for laying polygonometric traverses by the benchmarks of profile lines, and the like; GPS - for coordinating benchmarks; digital cameras and unmanned aerial vehicles to improve photogrammetric methods for studying deformations.

It has been proven that the remote methods of monitoring the deformations are effective, which make possible to study an object at a certain distance from it. The methods using electronic total stations operating in the "unreflected" mode and photogrammetric methods using scanners and digital cameras mounted on aerial vehicles or directly on the ground are among such methods. Surveying from an aerial vehicle allows to cover larger areas than from the ground, therefore the use of unmanned aerial vehicles made it possible not only to reduce the cost of the entire complex of work on monitoring the deformations of the day surface and objects located on it, but also to improve the accuracy of determining the deformation parameters due to a larger scale images and capabilities of modern lenses.

In this paper, a method is proposed for monitoring the deformations, which differs from those discussed above in high accuracy, convenience and low cost. There will be no expected result without a detailed analysis of the survey equipment that can be used. Therefore, considerable attention in this paper is focused on the choice of an effective option for surveying and processing the obtained images.

\section{Results and discussions}

Within the framework of the treaty adopted between Kryvyi Rih National University and PJSC "Central Iron Ore Enrichment Works", since 2011 an observation station has been established on the territory of the "named after Ordzhonikidze" mine and adjacent territories, on the benchmarks of the profile lines of which regular surveying observations are performed. Monitoring the position of the profile lines benchmarks makes possible to 
determine the values of vertical and horizontal deformations not only of the day surface, but also of buildings and structures located on it.

Experimental work on monitoring the deformations of buildings and structures located in areas of the terrain exposed to the influence of underground mining operations was performed for objects located in the zone of the "named after Ordzhonikidze" mine influence. Some of the buildings for $3-5$ years have fallen into disrepair. Garment factory workshop is among them. The building of the Garment factory was decommissioned, the equipment was removed from it and people have no an access to it. The values of dangerous deformation have created systems of fractures in the walls of the building. In addition, the south-eastern corner of the building has significant values of subsidence.

It is known that it is reasonable to study the state of buildings, structures and the earth's surface using high-precision surveying and geodetic methods. The regular studies of deformation processes occurring at various objects make it possible to timely warn of danger and to predict their further state. With regard to the building of the Garment factory workshop, these works are necessary to clarify the date of the collapse and to avoid accidents. Figure 1 shows the results of monitoring the horizontal and vertical deformations on the benchmarks of the profile line which is located next to the studied buildings. The maximum deformations are observed on the benchmarks near the building of the sewing workshop.

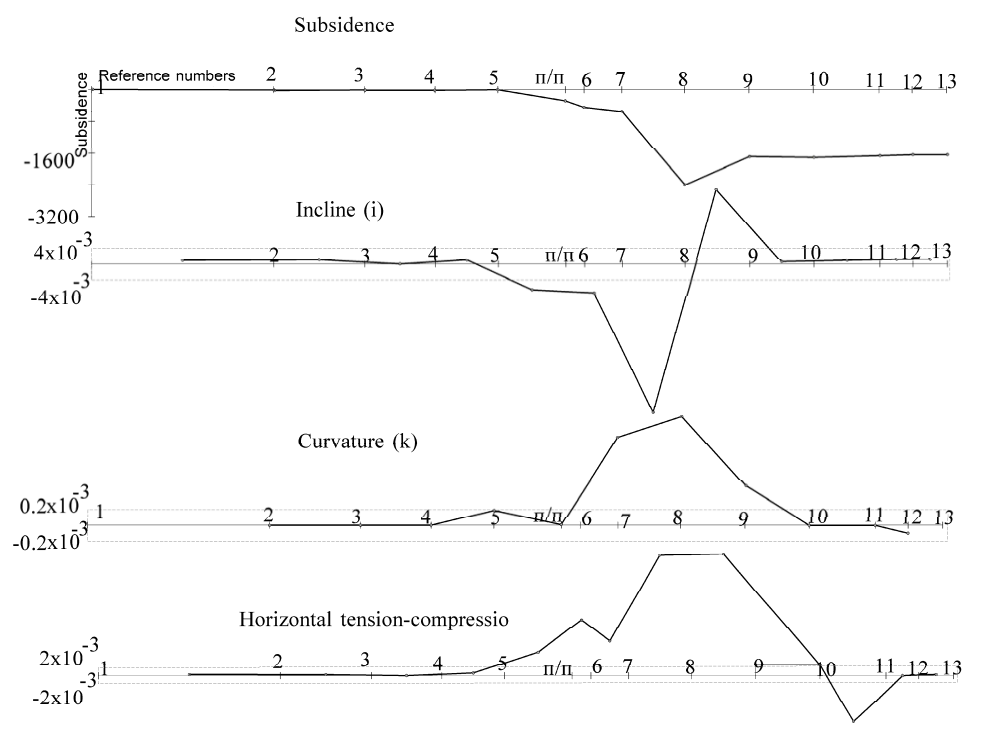

Fig. 1. Values of horizontal and vertical deformations.

At the initial stage of observations, 12 wall marks were laid in the building of the sewing workshop, and at the second stage -9 more. Since the profile line of the observation station is in the immediate vicinity of the building, the displacement process throughout the entire site can be controlled more completely.

The benchmarks stability was determined using measurements made with an electronic total station and a highly-accurate leveling device. Leveling was performed on the heads of the wall marks. Points $6 / 5$ and 6/4, from which the benchmarks stability is checked, are linked by two Topcon Hiper PLUS GPS-receivers to the benchmark, which is out of the mining operations influence at a distance of more than $300 \mathrm{~m}$. 
The actual accuracy of determining the benchmarks position in the planned position, according to the results of processing measurements in the CredoDAT program, does not exceed $\pm 2 \mathrm{~mm}$. Using a Zeiss Ni3 highly-accurate leveling device allows to determine the elevation points of benchmarks with accuracy $\pm 1 \mathrm{~mm}$.

In addition to the classical surveying and geodetic methods of monitoring the state of buildings and structures, the following are also used: geophysical methods such as RAP (Resonant Acoustic Profiling), photogrammetric and the like. Photogrammetric research methods make possible to fix and memorize the spatial position of separate structural elements and the entire building at one physical moment. An important advantage is also the fact that the monitoring of deformations is performed remotely, ensuring the performers safety.

The accuracy of determining the spatial coordinates, when performing photogrammetric work, is influenced by a number of factors, one of which is the image geometric distortion by the lens. Previously, there were difficulties in performing research with lens, since it could be made by only a few specialized organizations. To solve exact metric problems, lenses with minimal distortion values were used. Nowadays, it is easy to create conditions for lens calibration, it can be done even at home, by using initial points or photographing a monitor with black-white geometric shapes with their subsequent mathematical processing. It is this method is used in the work.

To improve the accuracy and reliability of the surveying results when using the photogrammetric method for monitoring the deformations of buildings and structures located above or near the mined-out space, the authors studied the distortion value for three lenses used in the observations: CANON LENS EF $50 \mathrm{~mm}$ 1:1.8 II; CANON LENS EF-S $24 \mathrm{~mm}$ 1:2.8 STM; MC-3M-5CA.

It is known that with photogrammetric methods of monitoring the earth's surface displacement and the deformations of buildings and structures, it is necessary not only to perform measuring work with high accuracy according to the obtained images, but also to have for this not distorted images.

Each of the studied lenses has both advantages and disadvantages. It is necessary to choose the most effective option for their application, which would use the advantages of these cameras and minimize their disadvantages when studying the displacements and deformations of hazardous areas above the mined-out space. Solving this problem is impossible without thorough research of the used lenses.

The studies performed are aimed at improving the quality of images. Photogrammetric lens distortion is a failure of the image similarity, which is systematic and can be determined by the formula:

$$
\Delta r=k_{1} r^{3}+k_{2} r^{5}+k_{3} r^{7}
$$

where $r$ is radius-vector of a point (the distance from the principal point of the image to the given point); $k_{1}, k_{2}, k_{3}$ are coefficients that can be determined, if to find the distortion values for at least three points of the image. Using them, the distortion for other points can be calculated by the formulas:

$$
\Delta x=x\left(k_{1} r^{2}+k_{2} r^{4}+k_{3} r^{6}\right), \Delta y=y\left(k_{1} r^{2}+k_{2} r^{4}+k_{3} r^{6}\right) .
$$

The results of lenses research are shown in Figs. 2 - 4. The graphs show the dependence of the image distortion value on the circle radius on which the studied point is located. The circle centre is located in the centre of the image. The smallest radial distortion values are obtained for the CANON LENS camera with a EF $50 \mathrm{~mm} \mathrm{1:1.8} \mathrm{II} \mathrm{lens.} \mathrm{The} \mathrm{radial}$ distortion value of this camera with the EF-S $24 \mathrm{~mm} \mathrm{1:2.8} \mathrm{STM} \mathrm{lens} \mathrm{is} \mathrm{unexpectedly}$ highest. 


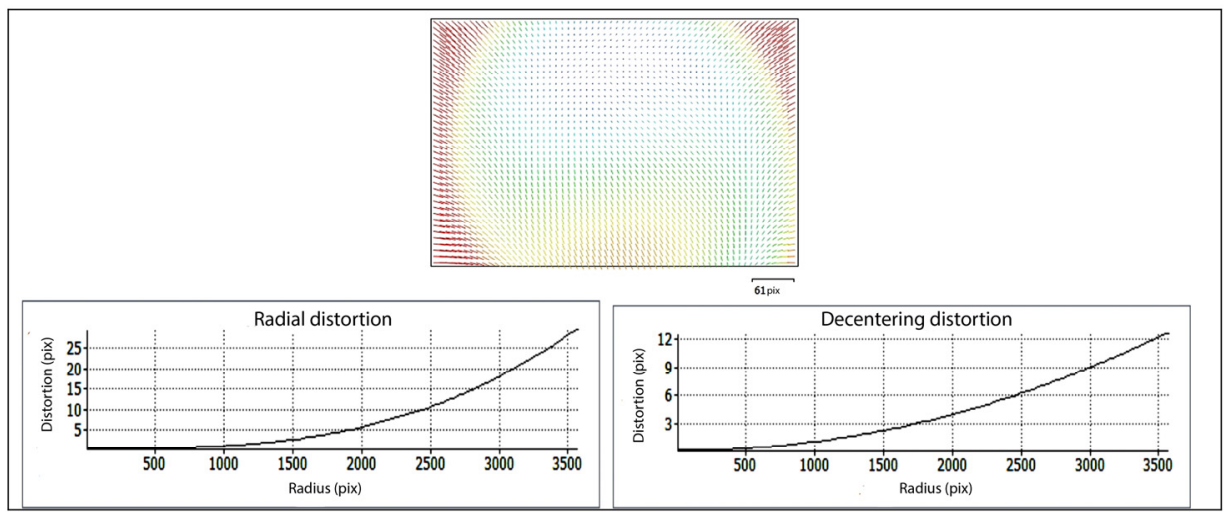

Fig. 2. The research results of the distortion value for the CANON LENS EF $50 \mathrm{~mm} \mathrm{1:1.8} \mathrm{II} \mathrm{lens.}$

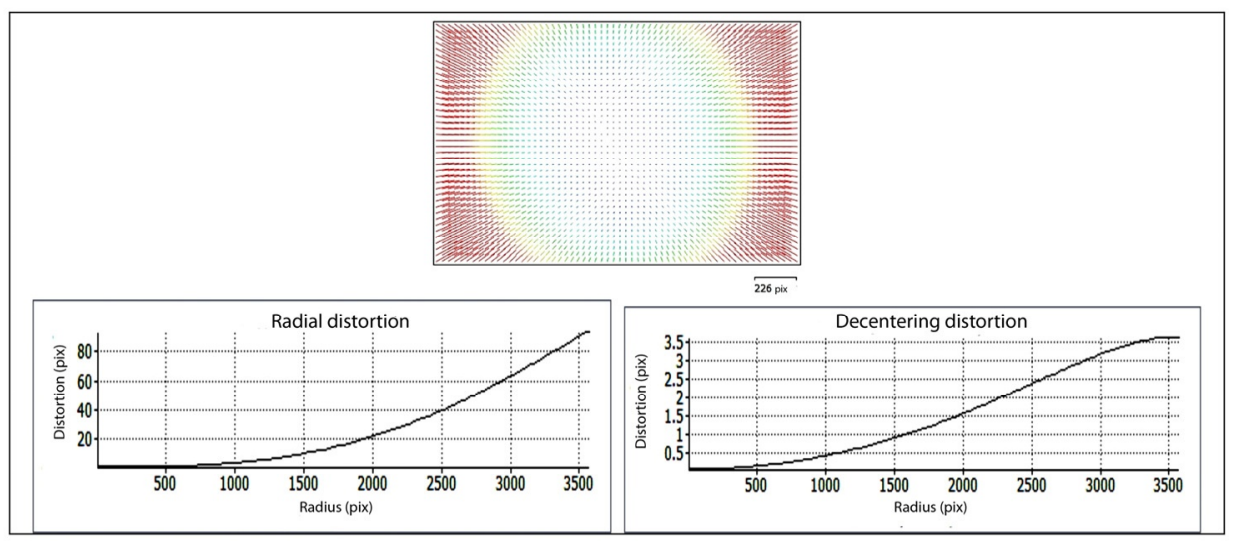

Fig. 3. The research results of the distortion value for the CANON LENS EF-S $24 \mathrm{~mm}$ lens.

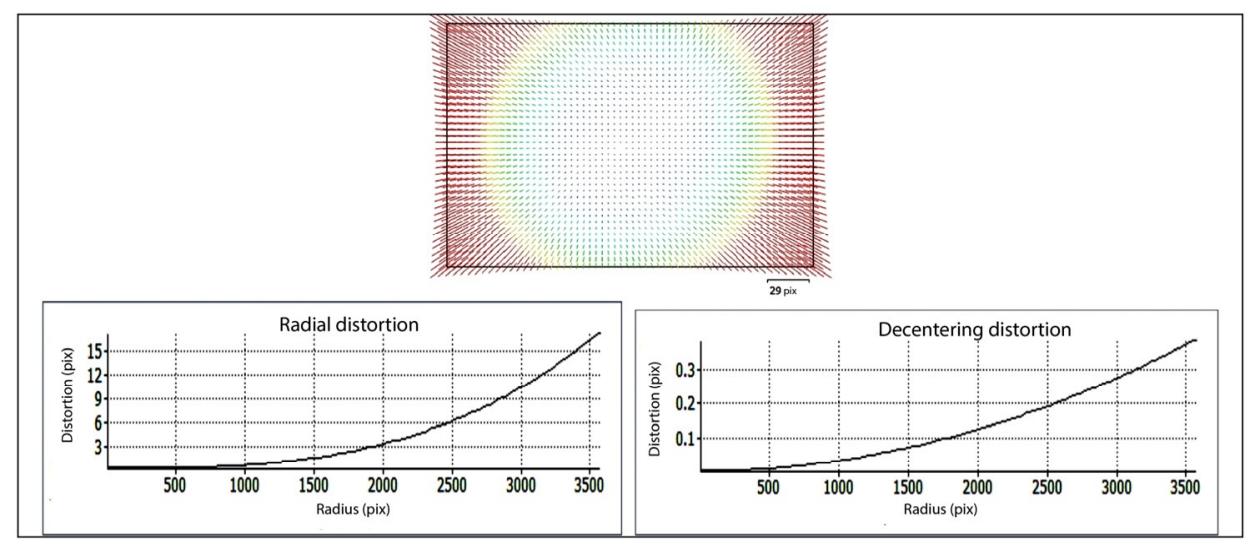

Fig. 4. The research results of the distortion value for the MC-3M-5CA lens.

It is known that typical preliminary data on the distortion value are available in the Internet. This data is loaded automatically when a network is available by identifying the lens model. For a CANON LENS camera with CANON LENS EF $50 \mathrm{~mm}$ 1:1.8 II and CANON LENS EF-S 24 mm 1:2.8 STM lenses, such data are known. 
Table 1 presents the characteristics of geometric distortions both typical and measured for the CANON LENS EF $50 \mathrm{~mm}$ 1:1.8 II and CANON LENS EF-S $24 \mathrm{~mm} \mathrm{1:2.8} \mathrm{STM}$ lenses, as well as the values of distortion coefficients. As can be seen from Table 1, typical elements differ from determined ones, therefore their use is limited and they cannot be taken into account when solving exact metric problems.

Under the condition of using the lens without any data on geometric distortion, as a result of monitoring the object, the errors appear at reference points ranging from $4 \mathrm{~mm}$ to $158 \mathrm{~mm}$.

Table 1. Values of geometric distortions for the lenses of a CANON LENS camera.

\begin{tabular}{|l|c|c|c|c|}
\hline \multirow{2}{*}{\multicolumn{1}{|c|}{ Parameters }} & \multicolumn{2}{c|}{ CANON LENS } & \multicolumn{2}{c|}{ CANON LENS } \\
& \multicolumn{2}{|c|}{ EF 50 mm 1:1.8 II } & \multicolumn{2}{c|}{ EF-S 24 mm 1:2.8 STM } \\
\cline { 2 - 5 } & typical & measured & typical & measured \\
\hline Image Resolution: pixels & $6000 \times 4000$ & $6000 \times 4000$ & $6000 \times 4000$ & $6000 \times 4000$ \\
\hline Focals (pixels) & & & & \\
Fx & 13835.0190625 & 14720.6 & 6744,87 & 6741.34 \\
Fy & 13835.0190625 & 14720.6 & 6744,87 & 6741.34 \\
\hline Optical center & & & & \\
Cx & 3006.9163022 & 3078.32 & 3027.41 & 2998.94 \\
Cy & 1927.8331335 & 2136.91 & 1989.06 & 2008.25 \\
\hline Radial distortion (Brown's & & & & \\
Model) & & & & \\
K1 & -0.09013795 & -0.0455885 & -0.1195726 & 0.00096997 \\
K2 & 0.037397627 & 0.0440742 & 0.1052112 & -0.0144061 \\
K3 & -1.55985987 & -5.01338 & -0.0022341 & 0.0336385 \\
\hline
\end{tabular}

The photographic survey of the sewing workshop building was performed using three lenses: CANON LENS EF $50 \mathrm{~mm}$ 1:1.8 II; CANON LENS EF-S $24 \mathrm{~mm}$ 1:2.8 STM; MC-3M-5CA, and the previous coordinates were determined using the Canon GP-E2 receiver, which makes possible to determine the coordinates in the WGS84 system with an accuracy of $3-5 \mathrm{~m}$. To do this, the Canon GP-E2 is inserted into the "hot shoe" and the coordinates are recorded into the EXIF-data of the digital photo. The receiver has a digital compass, but its value cannot be read through specialized programs from EXIF-data (except for Agisoft Metashape Professional).

During the photographic survey of the sewing workshop building, there were certain restrictions, namely, the lack of space. At a distance from the building, other objects fell into the field of view, and from a distance of about $15 \mathrm{~m}$, a large-scale survey was obtained, but with a smaller coverage of the object. In case of large-scale photographic survey, small areas of the building fall in the field of view, thereby resulting in a large number of images.

To improve the accuracy of measurements from the images, the points were marked with paint on the building additionally, and the spatial coordinates of 15 identification marks were determined. As a result of the photographic survey, a digital model has been obtained in the form of a 3D point cloud. The digital model is of high degree of detail and resolution. As a result of measuring the 3D model, the spatial coordinates of the points $X, Y$, and $Z$ have been obtained and compared to the coordinates of these points, which were obtained using an electronic total station and leveling device. This made it possible to determine the accuracy of photogrammetric method for monitoring the earth's surface displacements and deformations of buildings and structures located above the mined-out space.

To solve the problem of choosing the most effective method of photographic survey and processing images of the studied object, 3D models were based on the images obtained by each of the three lenses, as well as the images obtained with different lenses, that is, by processing simultaneously different-scale images, detail and area of covering the object by 
photographic survey. This uses the maximum possible object coveraging during photographic survey with the use of a lens with smaller focal length $(24 \mathrm{~mm})$ and high degree of detail and resolution of a lens with a long focal length $(50 \mathrm{~mm})$.

Figs. 5 and 6 show the errors in determining the coordinates of points by the images obtained with the CANON LENS EF $50 \mathrm{~mm} \mathrm{1:1.8} \mathrm{II} \mathrm{(in} \mathrm{pink} \mathrm{colour),} \mathrm{with} \mathrm{the} \mathrm{CANON}$ LENS EF-S $24 \mathrm{~mm}$ 1:2.8 STM (in blue), and using images obtained with three cameras, namely, CANON LENS EF $50 \mathrm{~mm}$ 1:1.8 II, CANON LENS EF-S $24 \mathrm{~mm}$ 1:2.8 STM, $\mathrm{MC}-3 \mathrm{M}-5 \mathrm{CA}$ (in green).

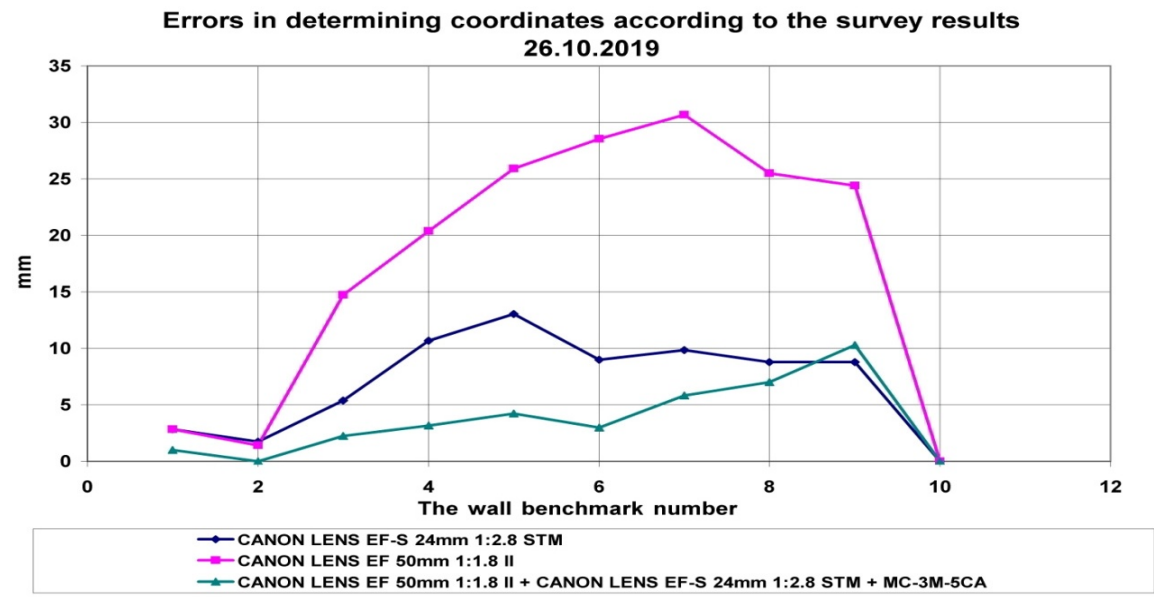

Fig. 5. Comparative characteristics of the accuracy of determining the planimetric coordinates of points by images obtained with different lenses on October 26, 2019.

Errors in determining coordinates according to the survey results 24.11.2019

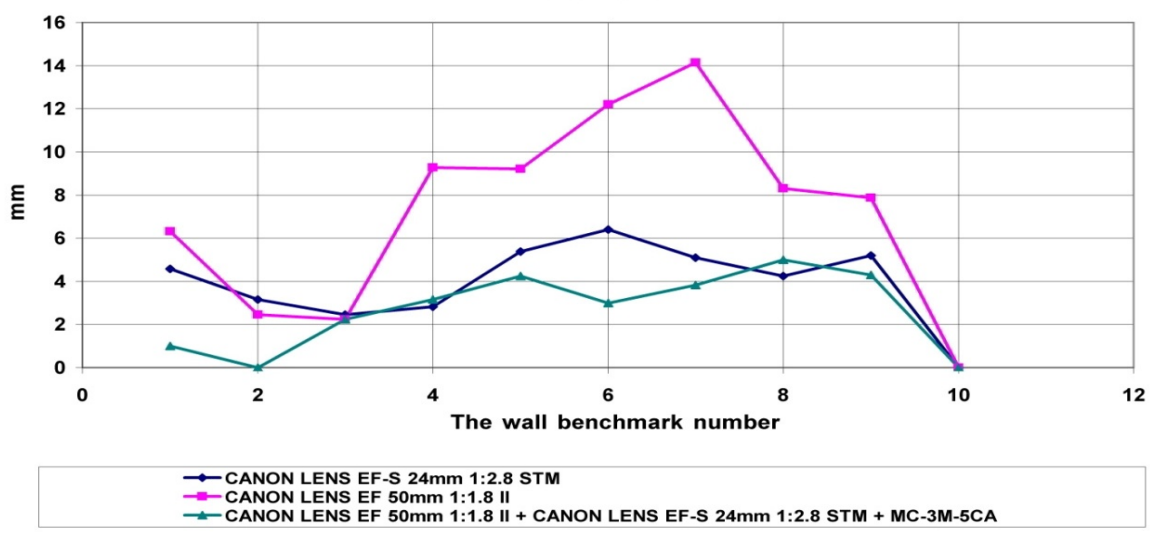

Fig. 6. Comparative characteristics of the accuracy of determining the planimetric coordinates of points by images obtained with different lenses on November 24, 2019.

It is evident from the graphs (Figs. 5 and 6) that the joint processing of images obtained by three different lenses significantly improves the accuracy of determining the coordinates.

Similar studies have been conducted on the accuracy of determining the heights of points, which were based on the results of processing images of the same-scale and 
simultaneous processing of different-scale images. A comparative characteristic of the accuracy of determining the coordinates and heights of points by images obtained with lenses with different focal lengths and angles of the field of view has revealed that with the simultaneous processing of these different-scale images, the determination accuracy is by $2-3$ times higher.

The scientific research novelty is in the fact that the developed methodology for digital imaging of buildings and structures located in the zones of underground mining influence is based on the simultaneous processing of different-scale images. The practical value of the proposed methodology is in improving the accuracy of determining the deformation values, which is confirmed by experimental work on objects located in the mine allotment of the "Named after Ordzhonikidze" mine, PJSC "Central Iron Ore Enrichment Works".

\section{Conclusions}

During the research into the negative impact of mining operations on the day surface and buildings, which is caused by mining a deposit of magnetite ferruginous quartzite in the field of the "named after Ordzhonikidze" mine, the necessity arose to correct the previously projected position of the displacement zone, to detail the value of the displacement angle and to develop a more efficient method for determining the deformation values using modern digital technologies.

To detail the position of the displacement zone boundaries, the authors use the results of their instrumental and visual surveying observations and domestic software. To correct the displacement zone position and to predict its further state, the observational data, performed by the authors since 2010, and the data of the mine surveying service for previous years are used.

The proposed photogrammetric method using different-scale images to determine the deformation values has testified its expediency during the study of the state of buildings located in areas hasardous for human presence. Obtaining a methodology would be impossible without studying the lenses characteristics, developing a method for simultaneous different-scale images processing, their fragmentation and the like. Studies on the use of digital imaging to determine the buildings deformations make it possible to draw a conclusion about the effectiveness of photographic survey using several lenses with different metric characteristics, followed by subsequent joint processing of the obtained different-scale images. The proposed methodology will improve the accuracy of determining deformation values with sufficient covering the object during the photographic survey and to ensure the safety of work.

This technique of joint processing of different-scale digital images can be used both in ground and airborne photographic survey. In cases when it is necessary to improve the accuracy of determining the planimetric or high-altitude position of points with sufficient coverage of objects during photographic survey, it is proposed to use joint processing of different-scale images, which takes into account the advantages of large-scale and smallscale images.

The authors of this paper express their sincere gratitude to the management of the PJSC "Central Iron Ore Enrichment Works" for the opportunity to conduct research at the facilities of the enterprise and to participate in joint work with the specialists of the mine surveying service during monitoring the deformations on the territory of the "named after Ordzhonikidze" mine and adjacent sites. 


\section{References}

1. Stupnik, M.I., Kalinichenko, V.O., Kalinichenko, O.V., Muzika, I.O., Fed'ko, M.B., \& Pismennyi, S.V. (2015). The research of strain-stress state of magnetite quartzite deposit massif in the condition of mine "Gigant-Gliboka" of central iron ore enrichment works (CGOK). Metallurgical and Mining Industry, (7), 377-383.

2. Stupnik, M., Kalinichenko, V, Pysmennyi S., Kalinichenko, O., \& Fedko, M. (2016). Method of simulating rock mass stability in laboratory conditions using equivalent materials. Mining of Mineral Deposits, 10(3), 46-51. https://doi.org/10.15407/mining10.03.046

3. Fedko, M.B., Muzyka, I.O., Pysmennyi, S.V., \& Kalinichenko, O.V. (2019). Determination of drilling and blasting parameters considering the stress-strain state of rock ores. Naukovyi Visnyk Natsionalnoho Hirnychoho Universytetu, (1), 37-41. https://doi.org/10.29202/nvngu/2019-1/20

4. Stupnik, M., Kalinichenko, O., Kalinichenko, V., Pysmennyi, S., \& Morhun, O. (2018). Choice and substantiation of stable crown shapes in deep-level iron ore mining. Mining of Mineral Deposits, 12(4), 56-62. https://doi.org/10.15407/mining12.04.056.

5. Pysmenniy, S., Shvager, N., Shepel, O., Kovbyk, K., \& Dolgikh, O. (2020). Development of resource-saving technology when mining ore bodies by blocks under rock pressure. E3S Web of Conferences, (166), 02006. https://doi.org/10.1051/e3sconf/202016602006

6. Dolgikh, A.V. (2014). Application of neural networks to investigations into the earth surface mined by underground operations. Geomatica, (1), 92-96.

7. Dolgikh, O.V. (2018). Use of capabilities of modern devices in investigating into slides on territories of mining enterprises. Kachestvo mineralnogo syria, 323-331.

8. Kalinichenko, V.O., Dolgikh, O.V., \& Dolgikh, L.V. (2019). Digital survey in studying open pit wall deformations. E3S Web of Conferences, (123), 01047. https://doi.org/10.1051/e3sconf 1201912301047

9. Dolgikh A.V., \& Dolgikh L.V. (2019). Definition of the ground surface deformations and constructions in the rock breakage zone. Traditions and innovations of resource-saving technologies in mineral mining and processing. Multi-authored monograph (pp. 300-309). Petrosani, Romania: UNIVERSITAS Publishing.

10. Dolgikh O., \& Dolgikh L. (2020). The study of the collapse zone by remote methods. E3S Web of Conferences, (166), 03002. https://doi.org/10.1051/e3sconf/202016603002

11. Wang, F., Jiang, B., Chen, S., \& Ren, M. (2019). Surface collapse control under thick unconsolidated layers by backfilling strip mining in coal mines. International Journal of Rock Mechanics and Mining Sciences, (113), 268-277. https://doi.org/10.1016/j.ijrmms.2018.11.006

12. Luan, H., Lin, H., Jiang, Y., Wang, Y., Liu, J., \& Wang, P. (2018). Risks Induced by Room Mining Goaf and Their Assessment: A Case Study in the Shenfu-Dongsheng Mining Area. Sustainability, 10(3), 631. https://doi.org/10.3390/su10030631

13. Hu, W.P. (2018). Comparative analysis on the numerical simulation and actual observation of surface movement in strip mining. Shaanxi Coal Min., (37), 91-94.

14. Guo, G., Li, H., \& Zha, J. (2019). An approach to protect cultivated land from subsidence and mitigate contamination from colliery gangue heaps. Process Safety and Environmental Protection, (124), 336-344. https://doi.org/10.1016/j.psep.2019.03.004

15. Kayabasi, A., Yesiloglu-Gultekin, N., \& Gokceoglu, C. (2015). Use of non-linear prediction tools to assess rock mass permeability using various discontinuity parameters. Engineering Geology, (185), 1-9. https://doi.org/10.1016/j.enggeo.2014.12.007

16. Howladar, M.F., \& Hasan, K. (2014). A study on the development of subsidence due to the extraction of 1203 slice with its associated factors around Barapukuria underground coal mining industrial area, Dinajpur, Bangladesh. Environmental Earth Sciences, 72(9), 3699-3713. https://doi.org/10.1007/s12665-014-3419-y

17. Deng, K.Z, Tan, Z.X, Jiang, Y., Dai, H.Y., Shi, Y., \& Xu, L.J. (2014). Deformation Monitoring and Subsidence Engineering. Xuzhou: China University of Mining and Technology Press. 
18. Fathi Salmi, E., Nazem, M., \& Karakus, M. (2017). Numerical analysis of a large landslide induced by coal mining subsidence. Engineering Geology, (217), 141-152. https://doi.org/10.1016/j.enggeo.2016.12.021

19. Guo, W.B., \& Xu, F.Y. (2015). Feasibility study on structures reconstruction in mining-affected areas. Journal Henan Polytechnic University, (34), 433-437.

20. Diao, X., Wu, K., Zhou, D., Wang, J., Duan, Z., \& Yu, Z. (2019). Combining subsidence theory and slope stability analysis method for building damage assessment in mountainous mining subsidence regions. PLOS ONE, 14(2), e0210021. https://doi.org/10.1371/journal.pone.0210021

21. Chen, C., Hu, Z., Wang, J., \& Jia, J. (2019). Dynamic Surface Subsidence Characteristics due to Super-Large Working Face in Fragile-Ecological Mining Areas: A Case Study in Shendong Coalfield, China. Advances in Civil Engineering, 2019, 1-16. https://doi.org/10.1155/2019/8658753

22. Liang, B., Yue, C., Chen, X. H., Wang, B., \& Sun, X. K. (2014). The Study of Deformation Monitoring Based on the Ground Three-Dimensional Laser Scanning Technology. Advanced Materials Research, (1022), 387-391. https://doi.org/10.4028/www.scientific.net/amr.1022.387

23. Diao, X., Bai, Z., Wu, K., Zhou, D., \& Li, Z. (2018). Assessment of mining-induced damage to structures using InSAR time series analysis: a case study of Jiulong Mine, China. Environmental Earth Sciences, 77(5). https://doi.org/10.1007/s12665-018-7353-2

24. Strzałkowski, P. (2019). Some Remarks on Impact of Mining Based on an Example of Building Deformation and Damage Caused by Mining in Conditions of Upper Silesian Coal Basin. Pure and Applied Geophysics, 176(6), 2595-2605. https://doi.org/10.1007/s00024-019-02127-1

25. Diao, X., Wu, K., Hu, D., Li, L., \& Zhou, D. (2016). Combining differential SAR interferometry and the probability integral method for three-dimensional deformation monitoring of mining areas. International Journal of Remote Sensing, 37(21), 5196-5212. https://doi.org/10.1080/01431161.2016.1230284

26. Benton, D., Iverson, S., Johnson, J., \& Martin, L. (2014). Photogrammetric monitoring of rock mass behavior in deep vein mining. In 33rd International Conference on Ground Control in Mining (pp. 221-227). Morgantown, USA: West Virginia University.

27. Benton, D.J., Warren, S.N., Sunderman, C.B., \& Richardson, J.R. (2018). A novel application of photogrammetry to ground convergence monitoring in underground excavations. Novel Optical Systems Design and Optimization XXI. https://doi.org/10.1117/12.2321247

28. Mutke, G., Kotyrba, A., Lurka, A., Olszewska, D., Dykowski, P., Borkowski, A., ... Barański, A. (2019). Upper Silesian Geophysical Observation System A unit of the EPOS project. Journal of Sustainable Mining, 18(4), 198-207. https://doi.org/10.1016/j.jsm.2019.07.005

29. Ou, D., Tan, K., Du, Q., Chen, Y., \& Ding, J. (2018). Decision Fusion of D-InSAR and Pixel Offset Tracking for Coal Mining Deformation Monitoring. Remote Sensing, 10(7), 1055. https://doi.org/10.3390/rs10071055

30. Pawluszek-Filipiak, K., \& Borkowski, A. (2020). Integration of DInSAR and SBAS Techniques to Determine Mining-Related Deformations Using Sentinel-1 Data: The Case Study of Rydułtowy Mine in Poland. Remote Sensing, 12(2), 242. https://doi.org/10.3390/rs12020242 